La experiencia en las decisiones: análisis en entidades financieras de Ocaña, Colombia

Experience in decisions: analysis with financial institutions in Ocaña, Colombia

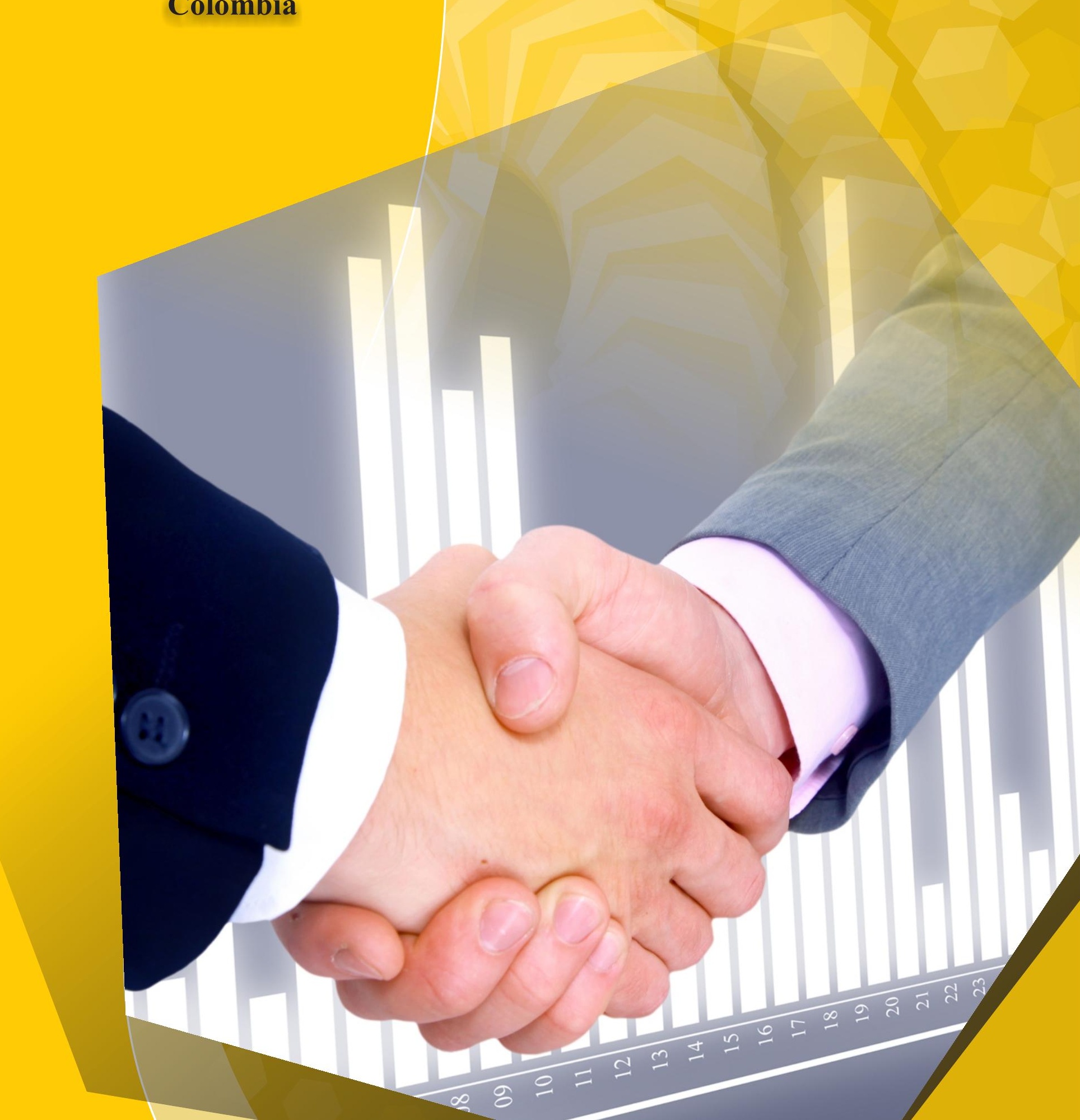




\title{
La experiencia en las decisiones: análisis en entidades financieras de Ocaña, Colombia ${ }^{1}$ Experience in decisions: analysis with financial institutions in Ocaña, Colombia
}

\author{
Nini Alejandra Reyes Campo ${ }^{2}$, José Gregorio Arévalo Ascanio ${ }^{3}$, \\ Genny Torcoroma Navarro Claro ${ }^{4}$ \\ Universidad Francisco de Paula Santander, Ocaña, Colombia
}

Artículo recibido en febrero de 2016; artículo aceptado en abril de 2016

Citación del artículo: Reyes, N, Arévalo, J.\& Navarro, G. (2016).La experiencia en las decisiones: análisis en entidades financieras de Ocaña, Colombia. I+D Revista de Investigaciones, 7(1), 24-31.

\begin{abstract}
Resumen
El objetivo del presente artículo es exponer algunos de los resultados obtenidos en el proyecto titulado"la toma de decisiones en los directivos de primer nivel en las entidades financieras de la ciudad de Ocaña", asociados principalmente con comprender la implicación existente entre la experiencia y el proceso de toma de decisiones en el contexto empresarial, específicamente en este tipo de entidades. La metodología utilizada se basó en un estudio cualitativo mediante la aplicación de entrevistas individuales que facilitaron el análisis y la presentación de los resultados, en los cuales se logró identificar la importancia que tiene la experiencia en el proceso decisor.
\end{abstract}

Palabras clave: Toma de decisiones, experiencia, intuición, gerente, instituciones financieras.

\section{Abstract}

The aim of this article is to present some of the results of the project "decision-making in senior executives in financial institutions in the city of Ocaña" mainly associated with understanding the relationship between experience and the decision-making process in the business context, specifically in such entities. The methodology used was based on a qualitative study by applying individual interviews that facilitated the analysis and presentation of results, in which it was possible to identify the implication of the experience in the decider process.

Keywords: Decision making, experience, intuition, manager, financial institutions.

\section{Introducción}

En cualquier organización empresarial quienes asumen el rol de decisores son precisamente los altos directivos, esperando con sus actuaciones generar perdurabilidad en la empresa. En tal sentido, Schutz (1970), citado por (Vélez, 2006), considera que los conocimientos y las expectativas que el individuo tiene, se forman con la experiencia y se convierten en la base de todas sus acciones personales; Schutz afirma también que la experiencia individual comprende todos los elementos que entran en la conciencia y se forman a través del contacto del individuo con el mundo natural y social que le rodea. Dicho brevemente, el conocimiento acumulado gracias a las experiencias vividas a través de los años, se convierte en un insumo valioso para disminuir la incertidumbre en el proceso de decisión.

${ }^{1}$ Artículo de investigación terminado, con enfoque cualitativo, desarrollado por el grupo de investigación GIDSE (categoría Colciencias B) de la Universidad Francisco de Paula Santander Ocaña.

${ }^{2}$ Administradora de Empresas de la Universidad Francisco de Paula Santander Ocaña, Correo: nareyesc@ufpso.edu.co

${ }^{3}$ Administrador de Empresas de la Universidad Francisco de Paula Santander Ocaña. Magíster en Administración de empresas de la Universidad Santo Tomás. Docente- investigador del grupo en Desarrollo Socio Empresarial GIDSE. Universidad Francisco de Paula Santander Ocaña (Colombia): Vía Acolsure, Sede Algodonal, PBX: 5690088 ext. 484. Correo: jgarevaloa@ufpso.edu.co

${ }^{4}$ Administrador de Empresas de la Universidad Francisco de Paula Santander Ocaña. Magíster en Dirección Estratégica de la Universidad Internacional de Puerto Rico, Docente- investigador del grupo en Desarrollo Socio Empresarial GIDSE. Universidad Francisco de Paula Santander Ocaña (Colombia): Vía Acolsure, Sede Algodonal, PBX:5690088 ext. 484. Correo: gtnavarroc@ufpso.edu.co 
En el marco del proyecto de investigación "La toma de decisiones en los directivos de primer nivel en las entidades financieras de la ciudad de Ocaña", en el que uno de sus objetivos fue analizar la influencia de la experiencia en la toma de decisiones, se realizaron entrevistas individuales que fueron aplicadas a los directivos de primer nivel de este tipo de entidades.

El presente artículo se divide en las siguientes partes: una primera en la que se sintetiza una revisión de literatura especializada publicada en las bases de datos Ebsco, Scopus, Science Direct, Scielo y Redalyc, donde se usaron como criterios de búsqueda, los descriptores: "Toma de decisiones", "Proceso de toma de decisiones" y "Experiencia", conviene subrayar que los descriptores se combinaron de diversas formas, con el propósito de extender los criterios de búsqueda. En la segunda parte se presenta la metodología utilizada, que fue de orden cualitativo, mediante la aplicación de entrevistas individuales en las que se indagó sobre el fenómeno específico de la "la toma de decisiones". La tercera parte corresponde al análisis de los resultados de las entrevistas aplicadas, cuya estructura se basa en tomar como eje la unidad de análisis "Experiencia" y, por último, se exponen las principales conclusiones de la investigación.

\section{Aproximación al concepto de experiencia}

La palabra experiencia proviene del latín experientia, que significa prueba o ensayo, por su parte, la Real Academia Española la define como el hecho de haber sentido, conocido o presenciado alguien algo o como la práctica prolongada que proporciona conocimiento o también como la habilidad para hacer algo y como el conocimiento de la vida adquirido por las circunstancias o situaciones vividas.

En este orden de ideas, para aportar en la comprensión del concepto de la experiencia, se presenta en este apartado una aproximación en la que se intenta describirlo. Una de esas definiciones la expone Amengual (2007), refiriéndose al concepto de Kant sobre la experiencia, quien la define como conocimiento empírico y al mismo tiempo afirma que aunque todo conocimiento empiece con la experiencia, no por eso procede todo él de la experiencia. Dicho de esta forma, la experiencia en quienes asumen cargos de primer nivel, puede ser concebida como elemento diferenciador de acciones y decisiones que transformen el rumbo de una organización empresarial. Por tal razón, Schutz, citado por (Vélez, 2006), considera que los conocimientos y las expectativas que el individuo tiene, formadas con la experiencia de su vida o historia personal, se convierten en la base de todas sus acciones personales.

Con base en lo anterior, considerar la experiencia adquirida como un factor determinante en el proceso decisorio, les da a quienes asumen este rol, una mayor capacidad para comprender la dinámica compleja de cada escenario, en el que ni existen problemas ni soluciones iguales.

(Martínez, Sánchez, Bechara, \& Román, 2006), plantean que cuando se va a tomar una decisión, se 'reviven' o actualizan en la corteza prefrontal ventromedial los estados emocionales que aparecían como consecuencia de las decisiones realizadas en anteriores elecciones similares, lo cual guía la decisión que se va a tomar. Dicho de manera breve, ésta es precisamente una de las razones por las cuales existen directivos de alto nivel cuyos procesos decisorios son iterativos, es decir, repetitivos. A medida que van aprendiendo de la experiencia van puliendo sus competencias para posteriores decisiones.

Por su parte, Días (1997) afirma que la experiencia no puede ser amorfa; se organiza a través de expresiones, relatos, narrativas, dramas sociales y realizaciones culturales (cultural performances) en general que se muestran y se comunican, esto es, que se hacen públicas. Vista de esta manera la experiencia, podría generarle a quienes toman decisiones en las empresas la posibilidad de convertirse en agentes transformadores de la realidad organizacional.

\section{Revisión de literatura}

En esta sección se presentan algunas de las investigaciones publicadas como artículos científicos en las bases de datos Ebsco, Scopus, Science Direct, Scielo y Redalyc, asociadas con la temática de la experiencia y su incidencia en el proceso de toma de decisiones:

Inicialmente Vélez (2006) realizó un estudio sobre el aprendizaje organizacional basado conceptualmente en las ideas de aprendizaje de Peter Senge, acción de Alfred Schutz, y decisión de Rubén Darío Parra, quienes consideraron las decisiones como un proceso cíclico siempre influenciado por los conocimientos, expectativas y experiencias pasadas, concluyendo quelas organizaciones aprenden por sus miembros y a través de los intercambios que éstos establecen con su entorno inmediato y el que traen consigo a través de sus trayectorias académicas y sus experiencias.

Del mismo modo Álvarez \& Alonso (2000) afirman en su estudio que los procesos de toma de decisiones se suelen basar en factores como la intuición, la experiencia pasada en situaciones similares y en la utilización de cierta información de base. De toda la información que posee el decisor y experiencia acumulada se extraen aquellas pautas repetidas a lo largo del tiempo a partir de las cuales se efectúan generalizaciones y predicciones y como consecuencia toda metodología que se emplee para la toma de decisiones debe contener la opción de incluir la experiencia acumulada como parte del proceso.

Por su parte Camejo \& Castro (2013) aplicaron una encuesta de manera individual y colectiva a diferentes personas de distintas organizaciones que quisieron 
participar voluntariamente, teniendo en cuenta que estuvieran desempeñándose en un cargo de alta a media dirección; como resultado del análisis encontraron que tomar una decisión por intuición o "corazonada" no es por fuerza independiente del análisis racional, más bien las dos formas se complementan. Un gerente que ha tenido experiencia con un problema o situación semejante puede actuar más rápidamente con lo que parecería una información.

Así mismo Useche (2014)en su investigación detectó que las personas van encontrando principios que consideran de forma personal reglas generales, pero en ocasiones tal proceso lleva a errores que se convierten en conductas sistemáticas, por consiguiente tal vez lo más conveniente sea que la empresa, empezando por sus altas directivas, reconozca la existencia de influencias del comportamiento como la experiencia en sus decisiones financieras, conozca sus impactos positivos y negativos e introduzca estos elementos explícitamente en su toma de decisiones, de forma que pueda aumentar la creación de valor para los accionistas y, en general, para la sociedad.

Por otro lado Chan (2011) concluye en su investigación que el factor de mayor importancia para los empresarios de la empresa mexicana, es la experiencia del management, lo que justifica la relevancia que han adquirido en las empresas los métodos de gestión de activos intangibles, como el cuadro de mando integral (balance scorecard). Este factor también aparece en el primer lugar de los estudios extranjeros analizados en el mismo estudio.

A su vez Pinzón (2007), a través de una investigación de carácter cualitativo, identifica que la carencia de información de tipo técnico, económico, comercial y de contexto, llevan a que el microempresario aprenda a resolver problemas tomando decisiones, donde la experiencia propia y la compartida es la que realmente tiene valor; así mismo resalta expresiones de sus entrevistados, como "más sabe el diablo por viejo que por diablo", cargadas de simbolismo y que a la vez se convierte en imaginarios de acción.

De la misma manera Hoyos (2011) mediante revisión bibliográfica y entrevistas semiestructuradas determinó las características más relevantes de los procesos de toma de decisiones de directivos de primer nivel de las Pymes del valle de Aburrá, definiéndolo como un proceso multifactorial el cual es afectado entre otros elementos por el ambiente, la edad y los procesos mentales de cada individuo y que aparece como un elemento diferenciador de acciones y decisiones, que evita que éstas sean repetitivas al posibilitar la adquisición de aptitudes, competencias, experiencias y conocimientos los cuales modifican la conducta, la interpretación y la visión de quienes toman las decisiones.

\section{Tipo de estudio}

\section{Método}

La investigación se trabajó con una metodología cualitativa desde el enfoque fenomenológico, entendido como un "estadio para el abordaje de la subjetividad del individuo, sus sentimientos, recuerdos, vivencias expresadas de manera oral, escrita o gráfica" (Leal, 2008, pág. 53) y en el que conviene resaltar que se orienta al abordaje de la realidad, partiendo del marco de referencia interno del individuo. Al mismo tiempo, es preciso señalar que la metodología permitió estructurar el eje analítico de la investigación a partir de la indagación de la lógica interna de un fenómeno específico: "la toma de decisiones".

\section{Participantes}

Por ser una población finita y relativamente pequeña, el tamaño de la muestra estuvo determinado por los directivos de primer nivel entrevistados que ejercen su función en las principales entidades financieras de la ciudad de Ocaña, lo cual significa que se pudo tener la participación de siete (7) directivos de este tipo de instituciones de la localidad.

Para la selección de los entrevistados se tuvieron en cuenta los siguientes criterios: directivo de primer nivel, entendido éste como la persona que ejerce un rol importante y decisivo dentro de la organización como director ejecutivo, jefe ejecutivo, gerente general, gerente de agencia entre otros y que pertenecen a instituciones financieras tal como Bancos, Cooperativas de Ahorro y Crédito, es decir las entidades que realizan operaciones de intermediación financiera y que tienen reconocimiento en la ciudad de Ocaña por su trayectoria.

En este apartado, es pertinente establecer la muestra con relación al número de personas entrevistadas, en este sentido, "no importa tanto el número de personas a las cuales se aplica el instrumento de investigación como sí la calidad de la información que se recoge"(Ruíz \& Abello, 2012).

\section{Materiales e instrumentos}

La investigación exigió la utilización de diferentes técnicas para recopilar los datos relacionados con la acción del decisor y su utilización por parte de los directivos de primer nivel de las entidades financieras tales como:

\section{Entrevistas}

Se realizaron entrevistas individuales cualitativas enfocadas y en profundidad, es de aclarar que la elección de las entrevistas, como proceso metodológico de recolección de información, se fundamentó en la intención de tener contacto directo con los sujetos de la investigación, en tanto la búsqueda señala el interés por comprender la experiencia y el conocimiento que estos sujetos tienen de su situación y de sus condiciones al tomar decisiones. 
Observación no participante: Consistió en la observación de los fenómenos sociales que ocurrían en las organizaciones dirigidas por los directivos seleccionados.

Observación participante: Estuvo en la realización de actividades con los directivos de primer nivel mientras se observaban sus actitudes.

Así mismo conviene decir que, para no comprometer la validez interna y del mismo modo construir criterios éticos en la presentación de los resultados, se reconoce que en "el ámbito de la investigación cualitativa el significado tradicional del concepto de validez ha sido reformulado, fundamentalmente, en términos de construcción social del conocimiento otorgando un nuevo énfasis a la interpretación" (Sandín, 2000, pág. 226), para el caso en estudio se registra el uso de una validez descriptiva ya que loshechos fueron recolectados en el informe sin ser distorsionados por los investigadores, lo cual se evidencia en la citación textual de algunos apartes de las entrevistas realizadas a los directivos, que fueron grabadas con el consentimiento de los informantes.

\section{Procedimiento}

Inicialmente se elaboró la guía para la realización de la entrevista. Posteriormente, se realizaron y transcribieron las primeras entrevistas, sobre las cuales se hizo un "análisis piloto" de cada una. Este análisis permitió corregir las preguntas en función de orientarlas de una manera más apropiada hacia los objetivos de la investigación.

Así mismo, se elaboró una matriz que resumiera las preguntas y respuestas de todos los entrevistados, con el fin de analizar la información de manera horizontal, para formar un concepto amplio y una primera aproximación a la comprensión del fenómeno de manera general, así como detectar diferencias significativas entre los informantes en cuestiones específicas.

\section{Resultados}

La toma de decisiones pone en juego numerosos procesos cognitivos, entre ellos el procesamiento de los estímulos presentes en la tarea, el recuerdo de experiencias anteriores y la estimación de las posibles consecuencias de las diferentes opciones. Como lo afirman Tranel D, Damasio A; citados por (Martínez, Sánchez, Bechara, \& Román, 2006, pág. 411)“todos estos procesos requieren la implicación de la memoria de trabajo y, en conjunto, de las denominadas funciones ejecutivas".

En este sentido, siempre habrá necesidad de aplicar el buen criterio y hacer uso de la experiencia por parte del decisor, elementos que, acompañados de buena información, procesada por medio de buenos modelos, permitirán producir mejores resultados para las organizaciones.
Para los directivos de primer nivel de las entidades financieras de Ocaña, el asunto de la experiencia ha tenidoun rol especial en el desempeño de sus funciones gerenciales, lo que indica el valor que estos directivos le dan al tema de la experiencia a la hora de determinar el curso de sus decisiones. Todos coinciden en el hecho de que el proceso de toma de decisiones es un espacio para el aprendizaje mediante experiencias, que se materializa desde el cambio de actitud del decisor. Es decir, la experiencia tiene un rol destacado y decisivo en el proceso de aprendizaje que se lleva a cabo cuando se toman decisiones, ésta misma se traduce en conceptos que se emplean, a su vez, como guías de elección de nuevas experiencias, como referentes de interpretación de una situación, como norte del cambio de actitud de la realidad y como lineamiento para el mejor uso de la información.

Uno de los directivos de primer nivel señala cómo la experiencia es un elemento clave para producir mejores resultados para la organización al afirmar que "la experiencia enseña mucho, uno no debe tomar decisiones con la cabeza caliente, pero hay momentos de verdad, en los que uno debe de respirar y calmarse, analizar la situación, qué es lo que se va hacer y cómo se va a hacer, de hecho la experiencia va dando la madurez que se requiere para actuar bajo presión, en donde uno debe calmarse y tomar agua y pensar qué es lo que se debe hacer, por lo cual no hay que dejarse llevarpor la inmediatez de la situación ... esas cosas no las enseñan en la universidad, solo se aprenden enla formación laboral, es la experiencia la que nos moldea".

Con las entrevistas realizadas se pudo comprobar que la experiencia le otorga a quienes toman decisiones una mayor capacidad de identificación de la complejidad en cada situación; es un proceso de aprendizaje a lo largo de los años y de experiencias decisorias.

Según los directivos de primer nivel entrevistados, uno de los elementos que incide de forma determinante en la experiencia para la toma de decisiones es el aprendizaje toda vez que le permite, a quien lo lleva a cabo, incorporar conocimientos que convocan mayores niveles de calificación, experiencia y capacidad de análisis, y, por ende, mayores ventajas competitivas para la organización.

En este orden de ideas, son las decisiones un espacio que bien podría generar el aprendizaje que requieren los directivos, en tanto permite incorporar conocimiento sin necesidad de dedicar tiempo a procesos formales de aprendizaje que les impliquen dejar sus responsabilidades laborales y estratégicas.

Por otro lado, existe un factor que se encuentra ligado a la experiencia, este factor es la intuición, definido como "percepción clara, íntima, instantánea de una idea o una verdad, tal como si se tuviera a la vista" por parte de la Real Academia Española. La intuición es desarrollada a través 
de la vivencia y la práctica, por ende, está estrechamente relacionada con la experiencia que desarrolla toda persona, y en este caso los directivos de primer nivel de las entidades financieras en la ciudad de Ocaña no se encuentran exentos de poseer o vivenciar esta "corazonada" o percepción intuitiva.

En las entrevistas realizadas llama la atención que la intuición es considerada también un factor determinante en la toma de decisiones por parte de los directivos de primer nivel de las entidades financieras de la ciudad de Ocaña. En el caso de la entrevista dirigida a otro directivo de primer nivel, señala la utilidad de la intuición, al afirmar que "en empresas como ésta, debemos tomar decisiones audaces, valientes, que definitivamente no todos las tomaríamos, por lo complejas que resultan. Aquí aparecen muchos fenómenos intuitivos en el ejercicio del proceso decisorio, que debemos considerar y por supuesto no pasar por alto; ya que en la toma de decisiones trascendentales, debo reconocer que la intuición juega un papel determinante tanto en el acierto como en el desacierto en las decisiones complejas, no se nos debe escapar nada importante, ni podemos dejarnos confundir por lo insignificante. Uno debe tener esa malicia indígena de la que sea habla, porque por lo menos el papel aguanta con todo y te pueden traer los documentos con las mejores cifras que tú quieras y puedas; y pues parece ser una excelente opción para crédito, pero más allá con la conversación, la charla, la entrevista, la visita; todo eso puede revertir la decisión inicial, por eso es tan importante la intuición en la toma de decisiones".

Análogamente, otro de los directivos de primer nivel sostiene "no muy a menudo me guío por la intuición para tomar mis decisiones al interior del banco, con lo cual no quiero decir que la descarto en su totalidad, debo reconocer que en algunas decisiones que he tomado la intuición ha sido clave, por tanto creo que la intuición es más importante de lo que parece, es esa especie de sexto sentido que tenemos los directivos, de hecho yo estoy muy atento a estas señales intuitivas que surgen de repente. Me sucede, que en ocasiones se me ocurren algunas ideas relacionadas con los problemas que tuve durante el día y es ahí donde me surge otro tipo de pensamiento que llamo intuitivo que me sirve para detectar oportunidades, tomar decisiones acertadas, encontrar soluciones creativas a los problemas".

Conforme a lo planteado anteriormente, se puede afirmar que el análisis de los datos fue desarrollado mediante múltiples lecturas de las entrevistas transcritas, por tanto lo que se desprende de los resultados es que el actuar de los directivos de primer nivel de las entidades financieras de Ocaña se apoya significativamente en la experiencia como en la intuición, es decir, es necesario acudir a estos dos conceptos para decidir en caso de inmediatez, ya que hay problemas en el contexto organizacional que requieren, en muchos casos, de soluciones urgentes.

\section{Discusión y Conclusiones}

La toma de decisiones pone en juego numerosos procesos cognitivos, entre ellos el procesamiento de los estímulos presentes en la tarea, el re-cuerdo de experiencias anteriores y la estimación de las posibles consecuencias de las diferentes (Martínez, Sánchez, Bechara, \& Román, 2006). En este sentido, las habilidades cognitivas, las percepciones, los valores, las creencias y las señales intuitivas que se integren por parte de los directivos de alto nivel de las organizaciones en su proceso de toma de decisiones terminan siendo clave en la elección de la mejor alternativa.

La situación anterior no es ajena al contexto organizacional en el que se ha investigado, es decir en las entidades financieras, teniendo en cuenta que los directivos de primer nivel entrevistados conciben la toma de decisiones como un proceso complejo y sistemático influenciado por diferentes variables unas más controlables que otras, en el que las vivencias anteriores sirven de referente en el accionar decisorio. La afirmación anterior es consecuente con lo planteado por Vélez (2006), quien expresa que muchosdirigentes tienen la idea de decisión como un proyecto integral, basado en un proceso sistemático con patrón de razonamiento, donde la experiencia y el juicio le ayudan a obtener mejores resultados.

Igualmente se encontró que el valor que se da a la experiencia por parte de los directivos de primer nivel de las entidades financieras de Ocaña es muy alto, pues consideran que basados en este factor se logra desarrollar una serie de habilidades que le permiten tomar decisiones más apropiadas; además, estos consideran que la formación académica no es suficiente para garantizar la efectividad del proceso, ya que se puede contar con la información necesaria, políticas, reglamentos, instructivos, guías etc., y al momento de elegir la mejor alternativa se hace necesario acudir al recuerdo de las experiencias vividas. Lo anterior es muy cercano a lo expresado por los autores(Martínez, Sánchez, Bechara, \& Román, 2006), quienes indican que los aspectos emocionales, derivados de la experiencia de situaciones parecidas, propias o vicarias y aquellos aspectos asociados a las consecuencias o al contexto en el que se da la decisión, desempeñan un papel determinante.

Con respecto a las señales intuitivas que son tenidas en cuenta por los directivos objeto de estudio en el momento de tomar sus decisiones, conviene decir que en su mayoría las consideran como un elemento que se encuentra ligado a la experiencia desarrollada a través de la vivencia y la práctica, en este caso los directivos de primer nivel de las entidades financieras en la ciudad de Ocaña no se encuentran exentos de poseer o vivenciar esta "corazonada" o percepción. En repetidas ocasiones, en la mayoría de sus respuestas, manifestaron la necesidad de incorporarla en la elección más apropiada en determinada 
situación, aquí vale la pena parafrasear a uno de los directivos quien respecto a la intuición afirma que hasta en los negocios personales surge la voz de la conciencia o se siente una corazonada que aparece instantáneamente sin que esté presente el razonamiento y nos dice "tenga cuidado que ahí hay algún problema, claro está que no en todos los negocios se puede actuar tomando como base la intuición (...)". Lo dicho hasta aquí es acorde con lo planteado por (García, Machado , \& Slemenson, 2001) en las decisiones tomadas por los directivos, aplica el pensamiento denominado intuitivo, que no excluye al pensamiento lógicoproposicional, ninguna persona opera solamente con un tipo u otro: se hace simultáneamente con ambos tipo de pensamiento, aunque en diferente grado.

En último término, es importante resaltar que otros aspectos no contemplados dentro la investigación, como la cultura organizacional y el ambiente de trabajo, inciden fuertemente en el proceso de toma de decisiones, tal como se evidencia en las entrevistas realizadas, en donde la gran mayoría de los informantes afirmaron que el proceso decisorio no es el mismo en todas las organizaciones y que, a pesar de que a menudo se presentan situaciones similares en organizaciones que se dedican a la misma actividad y con las mismas alternativas de actuación, su respuesta ha sido diferente, teniendo en cuenta que cada empresa adopta un modelo de decisión donde se caracterizan algunas por ser más arriesgadas y otras por ser más conservadoras.

Así pues, con base en el estudio realizado se puede notar que sí es necesario profundizar en la comprensión de otras variables de las que depende la toma de decisiones en el contexto organizacional de las entidades financieras, las cuales podrían estar asociadas con el ambiente externo, los modelos mentales, el comportamiento, el riesgo y su previsión. En tal sentido, se precisa una mayor profundización en las investigaciones, que permitan desarrollar un constructor más sólido sobre la comprensión del proceso decisorio en los directivos de cualquier tipo de empresa.

\section{Agradecimientos}

La Universidad, mediante la División de Investigación y Extensión DIE, vincula a docentes, administrativos y estudiantes para que participen en la ejecución y desarrollo de proyectos de investigación. Vale la pena también resaltar el apoyo de la Facultad de Ciencias Administrativas y Económicas y específicamente al programa de Administración de Empresas, plan de estudios al que se encuentran adscritos los docentes y estudiantes involucrados en el proyecto.

\section{Referencias}

Álvarez, Y., \& Alonso, M. (2000). El proceso de toma de decisiones en entornos complejos: Una aplicación metodológica. Universidad de Oviedo.
Amengual, G. (2007). El Concepto de la Experiencia: De Kant a Hegel. Tópico(15), pp. 5-30.

Arredondo , F., \& Vásquez, J. (2013). Un modelo de análisis racional para la toma de decisiones gerenciales. Cuadernos de Administración, 26(46).

Camejo, J., \&Castro, A. (2013).¿Es la intuición un método para la toma decisiones gerencial?. Recuperado el $12 \mathrm{~d}$ e D i c i e m b r e d e 2015 , d e http://repository.urosario.edu.co/bitstream/handle/10336/ 4684/1015405134-2013.pdf? sequence $=5$

Chan, M. (2011). Factores no financieros determinantes en las decisiones de inversión. 6(2). Global Conference on Business and Finance Proceedings.

Corrales, E. (Agosto de 2010). La intuición como proceso cognitivo. Comunicación, 19(002), pp. 33-42.

Días, R. (1997). La vivencia en circulación. Una introducción a la antropología de la experiencia. Alteridades, pp. 5-15.

García, P., Machado , E., \& Slemenson, P. (2001). Lógica de la Intuición. Una aplicación de la metodología borrosa al análisis del pensar. Cuadernos del Cimbage(4), pp. 51-79.

González, P., \& Bermúdez, T. (2008). Una aproximación al modelo de toma de desiciones usado por los gerentes de las micro, pequeñas y medianas empresas ubicadas en Cali, Colombia.

Hoyos, J. (2011).La toma de decisiones vista como un proceso de aprendizaje para los directivos de primer nivel en PYMES del Valle de AburráObtenido de https://repository.eafit.edu.co/handle/10784/115\#.VwQtX $47 \mathrm{kcho}$

Leal, N. (2008). El método fenomenológico: Principios, momentos y reducciones. Revista Informe de Investigaciones Educativas, 1, 52-60.

Martínez, J., Sánchez, J., Bechara, A., \& Román, F. (2006). Mecanismos cerebrales de la toma de decisiones. Revista de Neurología, 7(42), pp. 411-418.

Pinzón, J. (2007). Incidencia de las prácticas culturales en la toma de decisiones de los empresarios de la microempresa en la ciudad de Ibagué. Recuperado el Enero $\mathrm{d} \mathrm{e} \quad 2016, \quad \mathrm{~d} e$ http://www.bdigital.unal.edu.co/1116/1/josevictorpinzon. 2007.pdf

Ruíz, I., \& Abello , J. (2012). La intuición estratégica como eje dinamizador en la toma de decisiones de la 
mipymes. Tesis, Universidad Nuestra Señora del Rosario, Bogotá.

Sandín, M. P. (2000). Criterios de validez en la investigación cualitativa: De la objetividad a la solidaridad. Revista de Investigación Educativa, 18(1), 223-242.

Useche, A. (2014). Exceso de confianza y optimismo en las decisiones de presupuesto de capital: las finanzas corporativas desde un enfoque centrado en el comportamiento. Universidad y empresa, 16(26), pp. 93114.

Vélez, M. (2006). El proceso de toma de decisiones como un espacio para el aprendizaje en las organizaciones. Revista Ciencias Estratégicas, 14, pp.153-169. 